\section{Destructive Arthropathy Associated with Dermatomyositis Sine Myositis Positive for Anti-Jo-1 and Anti-Cyclic Citrullinated Peptide Antibodies}

\section{To the Editor:}

Polymyositis (PM) associated with anti-synthetase antibodies is often accompanied by arthritis, but it is usually mild and self-limiting ${ }^{1}$. Subluxing arthropathy associated with anti-Jo-1 antibody (anti-Jo-1)-positive PM or dermatomyositis (DM) has been described as a distinct subset of $\mathrm{PM} / \mathrm{DM}^{2,3}$. It is characteristically a deforming, predominantly nonerosive arthropathy associated with subluxation of the interphalangeal (IP) joints, especially those of the thumbs. We encountered 2 patients who had severe, deforming, destructive arthropathy associated with DM sine myositis and who were positive for anti-Jo-1 and anti-cyclic citrullinated peptide (anti-CCP) antibodies. Both patients fulfilled the American College of Rheumatology (ACR) criteria for rheumatoid arthritis (RA).

Patient 1. In 1996, a 57-year-old Japanese woman was referred to our hospital with dyspnea on exertion. She had Gottron's sign in her hands, elbows, and knees, but there was no weakness, arthralgia, or Raynaud's phenomenon. Interstitial lung disease (ILD) was detected by chest radiography. Serum creatine kinase (CK) was normal, anti-Jo-1 was positive at $1: 2$, and rheumatoid factor (RF) and anti-SSA antibody were negative. She was diagnosed as having DM sine myositis. In 2000, prednisolone 40 $\mathrm{mg} /$ day was started due to worsening of her ILD. When her prednisolone therapy was tapered, arthralgia of the hands gradually developed. RF became positive at 1:320, and a diagnosis of RA was made in the same year. She had arthritis of the distal interphalangeal (DIP), proximal interphalangeal (PIP), and metacarpophalangeal (MCP) joints, as well as the wrists, neck, knees, ankles, and metatarsophalangeal (MTP) joints. In 2006, a radiograph of the hands showed severe destruction of the finger joints (Figure 1). She also had dorsal subluxation of the toes, severe anterior atlantoaxial subluxation (AAS) of the cervical spine with erosion of the odontoid process, and rheumatoid nodules. Mild pulmonary hypertension was detected by echocardiography. Although antinuclear antibody (ANA) was negative, her RF titer rose further to 1:5120, while anti-Jo-1 was 1:8 and anti-CCP became positive at $109 \mathrm{U} / \mathrm{ml}$ (normal $<4.5 \mathrm{U} / \mathrm{ml}$ ).

Patient 2. In 1998, a 56-year-old Japanese woman was referred to hospital with shortness of breath. She had no arthralgia, weakness, Raynaud's phenomenon, or Gottron's sign. A chest radiograph revealed ILD. Serum CK was normal, ANA, RF, and anti-SSA antibody were negative, but anti-Jo-1 was positive at 1:2. PM/DM preceded by ILD was diagnosed, and treatment was started with prednisolone $30 \mathrm{mg} / \mathrm{day}$. With tapering of her prednisolone therapy, mechanic's hands, Gottron's sign, and hand arthralgia developed. In 2002, she developed generalized arthritis and RF became positive at 1:160, leading to a diagnosis of RA. She had involvement of the DIP, PIP, and MCP joints, as well as the wrists, elbows, shoulders, neck, knees, ankles, and MTP joints. Her RA was resistant to various diseasemodifying antirheumatic drugs. A recent radiograph of the hands shows marked ulnar deviation at the MCP joints (Figure 2). She also had dorsal subluxation of the toes, severe anterior AAS of the cervical spine with erosion of the odontoid process, and rheumatoid nodules. Serum RF increased further to 1:5120, and anti-CCP was extremely high at $1520 \mathrm{U} / \mathrm{ml}$. On the other hand, anti-Jo-1 became negative. Serum that had been stored in 2000 was negative for anti-CCP.

Among patients with PM/DM, the frequency of anti-CCP positivity is reported to be $27.3 \%-30 \%{ }^{4,5}$, although the titer is far lower than in RA. In rheumatic diseases other than RA, there is a high prevalence of joint symptoms among patients with anti-CCP positivity ${ }^{4,6}$. Considering that radiographic joint damage is more severe in RA patients who are positive for anti-CCP ${ }^{7}$, it is possible that anti-CCP-positive patients with $\mathrm{PM} / \mathrm{DM}$ would also display worse joint destruction.

Our patients both had high anti-CCP titers, which corresponded to the levels seen in RA. This is reasonable, since both patients satisfied all 7 ACR criteria for RA. The distinction between PM/DM with subluxing

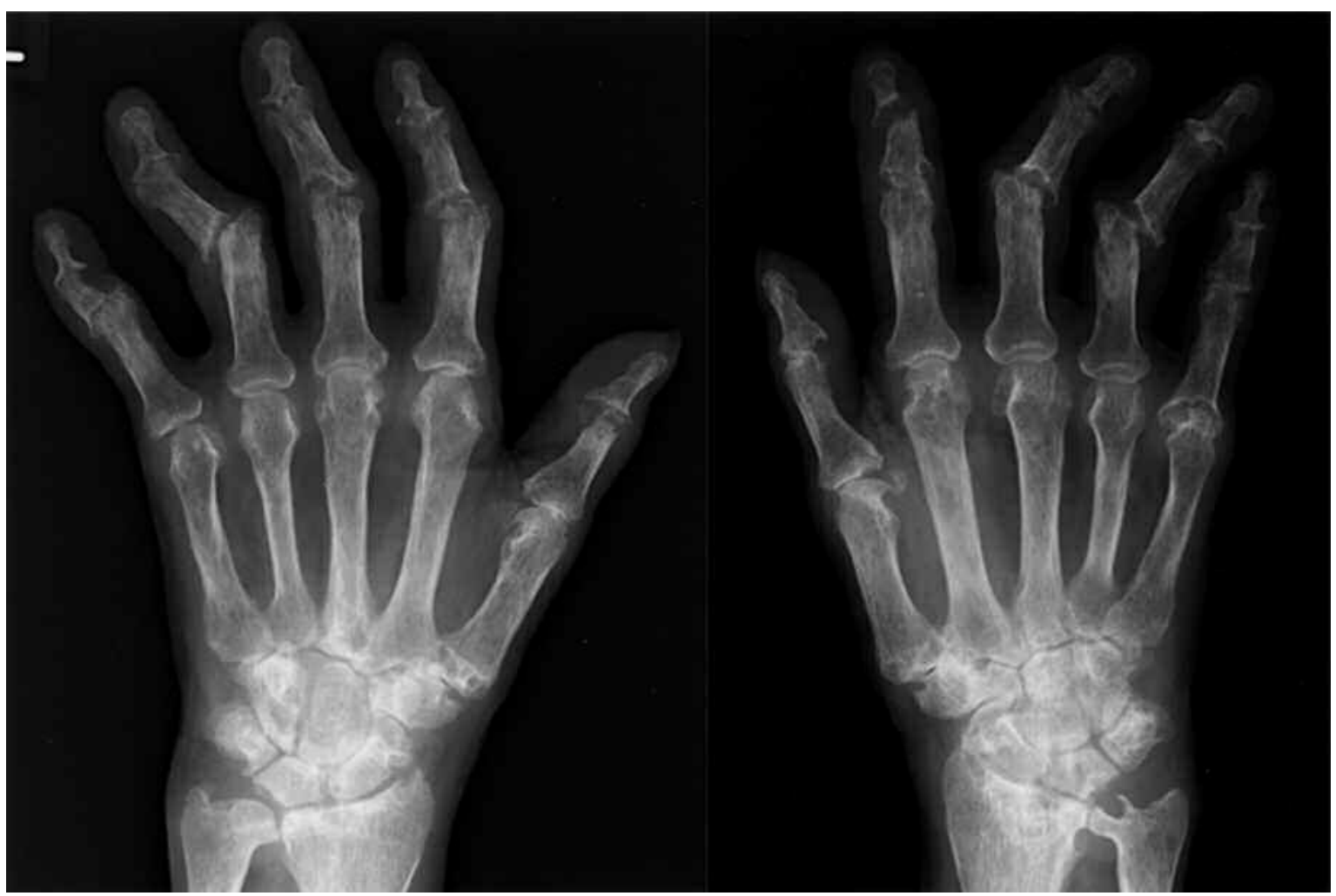

Figure 1. Patient 1; radiographs of the hands show severe destruction, osteolysis, and loss of alignment in the DIP and PIP joints. Typical erosions can also be seen on the ulnar styloid process, radius, and MCP joints. 


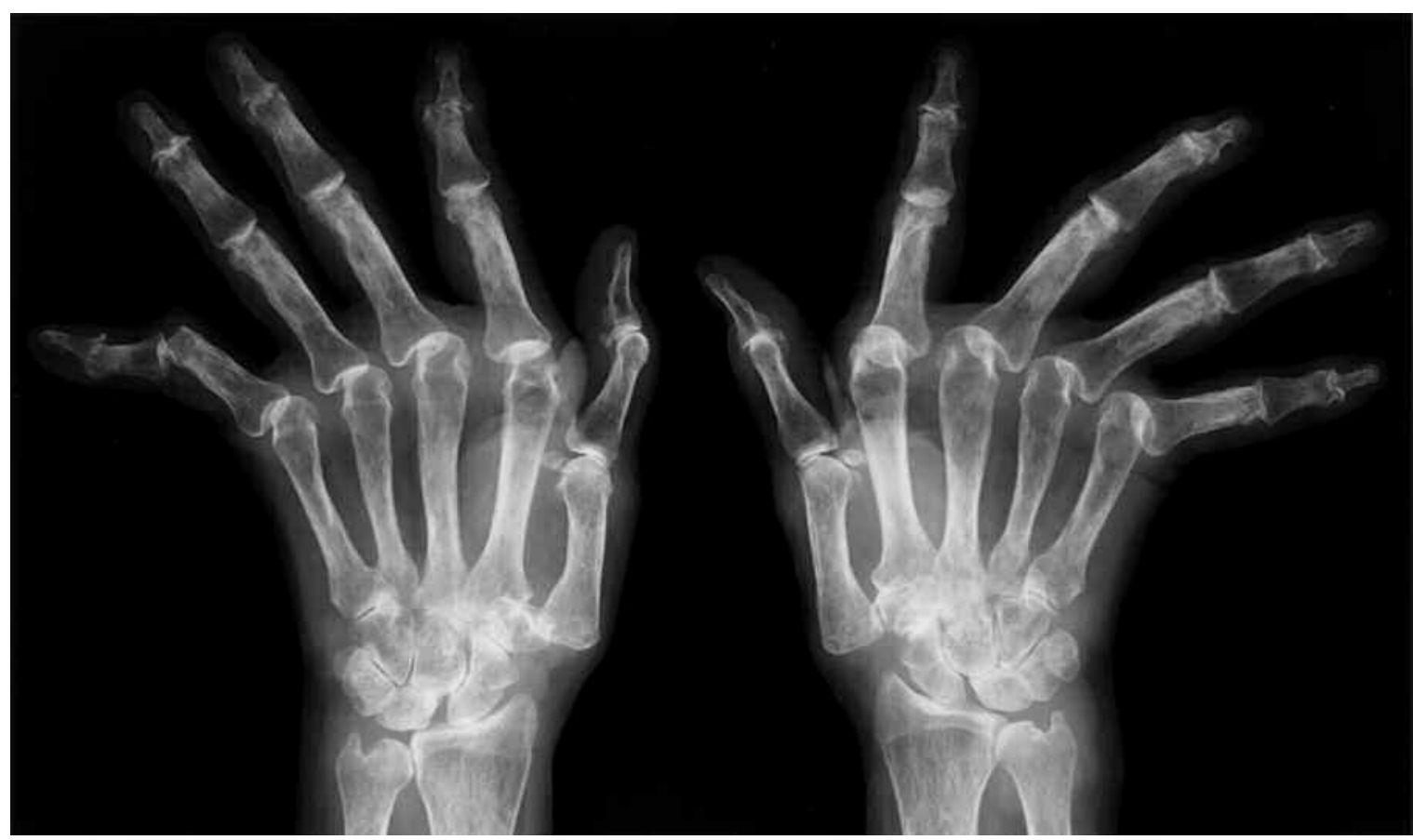

Figure 2. Patient 2; radiographs of the hands show nonerosive ulnar subluxation of the MCP joints is dominant, although there are erosions of the DIP joints and left fifth PIP joint subluxation.

arthropathy and destructive arthropathy (or overlap with RA) is not clear. Among patients who have subluxing arthropathy with antisynthetase syndrome, one-third fulfil the ACR criteria for $\mathrm{RA}^{3}$, and they may have erosions and RF positivity ${ }^{2,3}$. In such cases, anti-CCP may help differentiate the 2 subsets, as well as radiological changes.

Association of PM/DM with RA is neither rare nor new. However, patients with antisynthetase antibodies occasionally lack clinical myositis ${ }^{1}$. Subluxing or deforming, nonerosive arthropathy in anti-Jo-1-positive patients sine myositis has been reported before ${ }^{8,9}$. Erosive arthropathy in amyopathic DM without anti-Jo-1 has also been described ${ }^{10}$, but the ACR criteria for RA were not fulfilled. Thus, anti-Jo-1-positive DM sine myositis overlapping with destructive RA is rare.

We suggest that destructive, erosive arthropathy in patients with anti-Jo-1-positive DM sine myositis is another subtype of the disease, which may also be classified as DM sine myositis overlapping with RA. Anti-CCP may be useful for distinguishing subluxing from destructive arthropathy.

TAKAO NAGASHIMA, MD, PhD; HIDETOMO SATO, MD;

SEIJI MINOTA, MD, PhD, Professor of Medicine, Division of

Rheumatology and Clinical Immunology, Department of Medicine, Jichi Medical University, Yakushiji 3311-1, Shimotsuke, Tochigi, 329-0498, Japan. Address correspondence to Dr. Nagashima;

E-mail: naga4ma@jichi.ac.jp

\section{REFERENCES}

1. Marguerie C, Bunn CC, Beynon HL, et al. Polymyositis, pulmonary fibrosis and autoantibodies to aminoacyl-tRNA synthetase enzymes. Q J Med 1990;77:1019-38.

2. Oddis CV, Medsger TA Jr, Cooperstein LA. A subluxing arthropathy associated with the anti-Jo-1 antibody in polymyositis/dermatomyositis. Arthritis Rheum 1990;33:1640-5.
3. Meyer O, Charlanne H, Cherin P, et al. Subluxing arthropathy: an unusual manifestation of the antisynthetase syndrome. Ann Rheum Dis 2009;68:152-3.

4. Aotsuka S, Okawa-Takatsuji M, Nagatani K, et al. A retrospective study of the fluctuation in serum levels of anti-cyclic citrullinated peptide antibody in patients with rheumatoid arthritis. Clin Exp Rheumatol 2005;23:475-81.

5. Matsui T, Shimada K, Ozawa N, et al. Diagnostic utility of anti-cyclic citrullinated peptide antibodies for very early rheumatoid arthritis. J Rheumatol 2006;33:2390-7.

6. Matsui T, Shimada K, Tohma S. Anti-cyclic citrullinated peptide antibody in rheumatic diseases other than rheumatoid arthritis. Clin Rheumatol 2006;25:610-1.

7. Zendman AJ, Vossenaar ER, van Venrooij WJ. Autoantibodies to citrullinated (poly)peptides: a key diagnostic and prognostic marker for rheumatoid arthritis. Autoimmunity 2004;37:295-9.

8. Queiro-Silva R, Banegil I, de Dios-Jimenez de Aberasturi JR, Belzunegui-Otano J, Gonzalez-Beneitez C, Figueroa-Pedrosa M. Periarticular calcinosis associated with anti-Jo-1 antibodies sine myositis. Expanding the clinical spectrum of the antisynthetase syndrome. J Rheumatol 2001;28:1401-4.

9. Ozturk MA, Unverdi S, Goker B, Haznedaroglu S, Tunç L. A patient with antisynthetase syndrome associated with deforming arthritis and periarticular calcinosis sine myositis. Scand J Rheumatol 2007:36:239-41.

10. Mok CC, Tsui EY, Chau SY. Erosive arthropathy in amyopathic dermatomyositis. Clin Exp Rheumatol 2003;21:409-10.

J Rheumatol 2009;36:9; doi:10.3899/jrheum.090183 